\title{
Comparative effectiveness of simultaneous administration of mifepristone and misoprostol versus interval regimen of mifepristone followed by misoprostol 12 hours apart in second trimester medical abortion
}

\author{
Arunima Saini, Preet Kamal Bedi, Nisha Bhagat*
}

Department of Obstetrics and Gynecology, Government Medical College, Amritsar, Punjab, India

Received: 14 April 2018

Accepted: 08 May 2018

\author{
*Correspondence: \\ Dr. Nisha Bhagat, \\ E-mail: nishabhagat07@yahoo.com
}

Copyright: $($ the author(s), publisher and licensee Medip Academy. This is an open-access article distributed under the terms of the Creative Commons Attribution Non-Commercial License, which permits unrestricted non-commercial use, distribution, and reproduction in any medium, provided the original work is properly cited.

\section{ABSTRACT}

Background: In second trimester abortion, medical methods are preferred. Prostaglandins are the most widely used. Amongst them, misoprostol is the most commonly used. Thus, the study was conducted to delineate the effectiveness of simultaneous administration of mifepristone and misoprostol versus interval regimen mifepristone followed by misoprostol 12 hours apart in second trimester medical abortion.

Methods: It was a prospective, single centered, comparative study conducted on 50 patients in Department of Obstetrics and Gynaecology, GMC, Amritsar coming for second trimester abortion, either elective or emergency, with gestational age between 12-20 weeks. Initially, 53 patients were enrolled in the study, 3 patients dropped out at different stages of study. Finally, 50 patients were enrolled and divided into two groups of 25 patients each by $1: 1$ randomization. In Group-A, mifepristone $200 \mathrm{mg}$ orally along with misoprostol $600 \mu \mathrm{g}$ vaginally were given simultaneously, followed by $400 \mu \mathrm{g}$ vaginal misoprostol every 4 hours for a maximum of five doses in 24 hours. Group-B initially received mifepristone $200 \mathrm{mg}$ per oral followed by 12 hours later misoprostol $400 \mu \mathrm{g}$ vaginally and then $400 \mu \mathrm{g}$ vaginal misoprostol every 4 hours for a maximum of five doses in 24 hours. Primary outcome measure was effectiveness of regimen in complete abortion, which was confirmed on pelvic ultrasound 1-week after the last dose. Secondary outcome measure was to compare the induction abortion interval (IAI), dose of misoprostol required and adverse drug reaction (ADR) among both the regimens. P-value $<0.05$ was taken as statistically significant.

Results: Mean age in Group-A was 25.68 \pm 3.79 years while in Group-B was 23.40 \pm 2.73 years. Both the regimens had success rate of $76 \%$ for complete abortion. However, IAI in Group-A was 5.9 \pm 4.47 hours whereas in Group-B was $9.6 \pm 5.07$ hours, which was statistically significant $(\mathrm{p}=0.009)$. A statistically significant difference was also observed in the mean dose of misoprostol between two groups that is, $1000 \pm 200 \mu \mathrm{g}$ and $1425 \pm 437.41 \mu \mathrm{g}$ respectively $(\mathrm{p}=0.01)$. Gestational age was related to IAI from 13 to 17.6 weeks in both groups $(p=0.01)$ while no significant relation was seen between them in more than 17.6 weeks of gestation $(\mathrm{p}=0.63)$.

Conclusions: Simultaneous administration of mifepristone and misoprostol showed better results than interval regimen in term of significant lesser induction abortion interval, lower dosages of misoprostol required with comparable success rates.

Keywords: Abortion, Induction abortion interval, Mifepristone and misoprostol 


\section{INTRODUCTION}

The word abortion derives from Latin aboriri that means 'to miscarry.' Abortion is defined as the spontaneous or induced termination of pregnancy before fetal viability. The National Centre for Health Statistics, Centre for Disease Control and Prevention, and World Health Organization (WHO) defines abortion as pregnancy termination before 20 weeks of gestation or a fetus weighing < 500 grams. ${ }^{1}$ Although most of the abortions are performed in first trimester, there is an urgent need for second trimester abortion either due to delayed diagnosis of fetal anomalies or failure to recognize an undesired pregnancy in first trimester. It constitutes 10$15 \%$ of all induced abortions worldwide. ${ }^{2}$

The termination of pregnancy in second trimester poses a great problem as there is higher rate of complications. Various methods of abortion in second trimester are extraovular (extra-amniotic) normal saline, laminaria tent, introduction of bougies, $40 \%$ formalin $(3 \mathrm{cc}$ ) in amniotic sac through abdominal needle, replacement of 100 cc amniotic fluid with $20-30 \%$ saline solution $(100 \mathrm{ml})$, intra-amniotic injection of $20 \%$ hypertonic saline and extra-amniotic injection of ethacridine lactate etc. Due to inadvertent adverse effects like intrauterine infection, disseminated intravascular coagulation (DIC), thrombo-embolism, cerebral infarction and acute renal failure, most of the above methods are obsolete and are replaced by safer methods e.g., oxytocin and prostaglandins., ${ }^{3,4}$ Medical abortion with mifepristone followed by a prostaglandin analogue is shown to be safe and effective. ${ }^{5}$

Prostaglandins are the most commonly used drug in second trimester of medical abortion. Major action of prostaglandin-E1, E2 and $F_{2 \alpha}$ is to soften and dilate the cervix commonly referred to as cervical priming (ripening) and an action on myometrium. ${ }^{6}$ Misoprostol is a synthetic PGE-1 analogue, taken orally or intravaginally that induces cervical ripening as well as strong uterine contractions, which leads to expulsion of a conceptus. There is a marked difference in bioavailability between oral administration where plasma peak level is reached in about 30 minutes compared to vaginally that was having three times higher bioavailability than oral administration. The side-effects due to prostaglandins are dose dependent and include abdominal pain, chills, shivering, fever, diarrhea, gastrointestinal lesions, focal cardiac necrosis, hepatic and renal tubular necrosis, respiratory and CNS depression. Mifepristone or RU-486 acts as an antagonist to progestational and glucocorticoid receptors; it suppresses transcription activation and thus results in anti-progestational activity and makes it a potential abortifacient. ${ }^{7}$ Clinical trials for termination of early pregnancy with 50-600 mg mifepristone plus a prostaglandin analogue achieved a success rate of 82 $97 \%$ with shortening of IAI. ${ }^{8}$
So, the present study was undertaken to compare the effectiveness of simultaneous administration of mifepristone and misoprostol versus interval regimen of mifepristone followed by misoprostol 12 hours apart in second trimester medical abortion.

\section{METHODS}

The present study was an open-labeled prospective, single centered, randomized comparative study conducted in Department of Gynaecology and Obstetrics, Bebe Nanaki Mother and Child Care Centre, Government Medical College, Amritsar for the duration of one and a half years (from Dec 2015 to May 2017) in second trimester medical abortions either elective or emergency. Initially, 53 patients were screened for the study; 3 patients dropped out at various stages of study, two as lost for follow-up and another developed hypersensitivity reaction. Finally, 50 patients were enrolled who gave written informed consent. The study was approved by the institutional ethical committee and conducted in accordance to the declaration of Helsinki, Geneva and Good Clinical Practice Guidelines.

\section{Inclusion criteria}

Patients with 12-20 weeks of pregnancy who fulfilled indications of MTP, as per guidelines of MTP Act of 1971 and comprised of missed abortion or intrauterine fetal death, congenitally malformed baby that are not compatible with life or women in need of abortion due to medical or obstetrical reasons were included.

\section{Exclusion criteria}

- Scarred uterus, ectopic pregnancy, grandmultipara

- Contraindications to mifepristone and misoprostol

- History of thrombo-embolism or liver disease

- A known history of or active medical disease

- An intra-uterine contraceptive device in-utero

- Severe uncontrolled bronchial asthma

- Incomplete abortion

- Heavy smoker of more than 20 cigarettes per day

- Breast feeding women.

Duration of pregnancy was ascertained by history, clinical and ultrasonographic examination. Patients were allocated into two groups of 25 patients each by $1: 1$ randomization. In Group-A (simultaneous regimen), mifepristone $200 \mathrm{mg}$ was given orally along with misoprostol $600 \mu \mathrm{g}$ per vaginum, followed by $400 \mu \mathrm{g}$ vaginal misoprostol every 4 hours for a maximum of five doses in 24 hours. Group-B (interval regimen), received mifepristone $200 \mathrm{mg}$ orally and misoprostol $400 \mu \mathrm{g}$ vaginally 12 hours apart, followed by $400 \mu \mathrm{g}$ vaginal misoprostol every 4 hours for a maximum of five doses in 24 hours. 
Injection tetanus toxoid (TT) intramuscularly was given to all patients and injection anti-D $300 \mu \mathrm{g}$ intramuscularly, if patient was $\mathrm{Rh}$ negative. Vitals were monitored every 4 hourly among both the groups. Any history of subsequent development of fever, vomiting, chest pain, diarrhea, breathing difficulty or any other side effects arising due to medication were recorded and treated. The continuation of treatment was abandoned in case of life threatening complication and promptly intervened as per the emergency guidelines. A follow-up pelvic-ultrasonography (USG) after 7 days was done to confirm the success rate of regimen for complete abortion following the last dose of misoprostol.

Primary outcome measure was to assess and compare the effectiveness of the regimens. It was hypothesized that both the regimens were equally effective. Secondary outcome measure was induction abortion interval (IAI), dose of misoprostol and adverse drug reaction (ADR).

The cases that either fail to expel products within 24 hours of first dose of misoprostol or showed retained products of conception on pelvic USG were labeled as failure. Expulsion in these patients was achieved by inserting intracervical Foley's, oxytocin infusion and surgical evacuation.

\section{Statistical analysis}

Data thus obtained were spread in Microsoft excel sheet and then transferred to statistical Package for Social Sciences (SPSS) version 23. Discrete data were expressed as frequency and percentages. Continuous data were summarized as numbers, mean with standard deviation. Unpaired t-test was used to compare different variables between two groups. $\mathrm{P}$ value of $<0.05$ was taken as statistically significant.

\section{RESULTS}

Out of 53 patients recruited in the study, 50 patients were finally enrolled with response rate of $94.33 \%$. Mean age in Group-A was 25.68 \pm 3.79 years and in Group-B was $23.40 \pm 2.73$ years. Maximum patients in Group-A (44\%) were second gravida while $64 \%$ in Group-B were primigravida with mean gravidity of $1.88 \pm 0.8$ and $1.88 \pm 1.53$ respectively.

In Group-A, $40 \%$ (10 out of 25) patients were nulliparous and $40 \%$ (10 out of 25) patients had parity-1 while in Group-B, 72\% (18 out of 25) patients were nulliparous. Missed abortion was the most common indication for abortion in both groups being $62 \%$ and $64 \%$ respectively. Maximum number of subjects (52\%) in Group-A had gestational age between 13-15.6 weeks whereas in Group-B, 52\% patients had gestation age between 18- 20 weeks with mean gestation age of $15.92 \pm 2.40$ weeks and $17.30 \pm 2.36$ weeks respectively. All the above parameters were statistically comparable in both the groups $(\mathrm{p}>0.05)$ (Table 1).
Table 1: Patient characteristics.

\begin{tabular}{|c|c|c|c|c|}
\hline Parameters & & Group-A & Group-B & $\begin{array}{l}P \text { - } \\
\text { value }\end{array}$ \\
\hline $\begin{array}{l}\text { Mean age } \\
\text { (years) }\end{array}$ & & $25.68 \pm 3.79$ & $23.40 \pm 2.73$ & 0.55 \\
\hline \multirow{2}{*}{ Locality } & Rural & $48 \%$ & $40 \%$ & \\
\hline & Urban & $52 \%$ & $60 \%$ & \\
\hline \multirow{2}{*}{$\begin{array}{l}\text { Educational } \\
\text { status }\end{array}$} & Literate & $68 \%$ & $84 \%$ & \\
\hline & Illiterate & $32 \%$ & $16 \%$ & \\
\hline $\begin{array}{l}\text { Mean } \\
\text { gravidity }\end{array}$ & & $1.88 \pm 0.83$ & $1.88 \pm 1.53$ & 1.00 \\
\hline Mean parity & & $0.8 \pm 0.7$ & $0.72 \pm 1.3$ & 0.70 \\
\hline $\begin{array}{l}\text { Mean } \\
\text { gestational } \\
\text { age }\end{array}$ & & $15.92 \pm 2.40$ & $17.30 \pm 2.36$ & 0.09 \\
\hline
\end{tabular}

On comparing IAI in both the groups, a statistically significant $(\mathrm{p}=0.009)$ difference was seen with mean IAI of $5.9 \pm 4.47$ hours and $9.6 \pm 5.07$ hours respectively. $88 \%$ of women in Group-A aborted within 8 hours of misoprostol insertion while only $36 \%$ in Group-B were aborted within 8 hours and 56\% took up to 16 hours for complete expulsion (Table 2).

Table 2: Induction abortion interval (IAI) in both groups.

\begin{tabular}{|c|c|c|c|c|}
\hline \multirow{2}{*}{ IAI } & \multicolumn{2}{|c|}{ Group-A } & \multicolumn{2}{|c|}{ Group-B } \\
\hline & No. & $\%$ age & No. & \%age \\
\hline$<4 \mathrm{hrs}$ & 08 & 32.0 & 0 & 0.0 \\
\hline 4-8 hrs & 14 & 56.0 & 09 & 36.0 \\
\hline $8-12 \mathrm{hrs}$ & 01 & 4.0 & 10 & 40.0 \\
\hline $12-16 \mathrm{hrs}$ & 01 & 4.0 & 04 & 16.0 \\
\hline $16-20 \mathrm{hrs}$ & 00 & 0.0 & 0 & 0.0 \\
\hline $20-24 \mathrm{hrs}$ & 00 & 0.0 & 0 & 0.0 \\
\hline$>24$ hrs (failure) & 01 & 4.0 & 02 & 8.0 \\
\hline Mean IAI (HRS) & \multicolumn{2}{|c|}{$5.9 \pm 4.47$} & \multicolumn{2}{|c|}{$9.6 \pm 5.07$} \\
\hline $\mathrm{P}$ value & \multicolumn{2}{|c|}{0.009} & & \\
\hline
\end{tabular}

At presentation, $48 \%$ and $60 \%$ women in each Group-A and $\mathrm{B}$ had cervical os admitting tip of finger. However, IAI shortened with progression of the cervical dilation and relationship of both has been depicted in Table 3 .

Table 3: Cervical dilatation and IAI in both groups.

\begin{tabular}{|lllllll|}
\hline $\begin{array}{l}\text { Cervical } \\
\text { dilatation }\end{array}$ & No & \% & IAI & No & $\%$ & IAI \\
\hline Closed & 04 & 16.0 & 6.5 & 06 & 24.0 & 9.8 \\
\hline Tip & 12 & 48.0 & 7.5 & 15 & 60.0 & 9.0 \\
\hline $\begin{array}{l}\text { Upto } 1.5 \\
\text { CM }\end{array}$ & 07 & 28.0 & 3.8 & 02 & 8.0 & 8.5 \\
\hline $1.5-2.5$ CM & 02 & 8.0 & 3.5 & 02 & 8.0 & 15 \\
\hline
\end{tabular}

Gestational age was significantly related to IAI ( $p=0.01)$ from 13 to 17.6 weeks in both groups while no relation was seen between them after 17.6 weeks $(p=0.63)$ with increase in IAI in both groups between 18-20 weeks (Table 4). 
Table 4: Effect of gestational age on IAI.

\begin{tabular}{|c|c|c|c|c|c|c|c|}
\hline \multirow{2}{*}{ Gestational age (weeks) } & \multicolumn{3}{|c|}{ Group-A } & \multicolumn{4}{|c|}{ Group-B } \\
\hline & No & $\%$ & Mean IAI & No & $\%$ & Mean IAI & P-value \\
\hline $13-15.6$ & 13 & 52 & $5.42 \pm 1.88$ & 08 & 32 & $10.18 \pm 5.97$ & 0.01 \\
\hline $16-17.6$ & 05 & 20 & $3.46 \pm 0.36$ & 04 & 16 & $7.12 \pm 2.71$ & 0.01 \\
\hline $18-20$ & 07 & 28 & $8.78 \pm 7.60$ & 13 & 52 & $10.15 \pm 5.12$ & 0.63 \\
\hline
\end{tabular}

dd

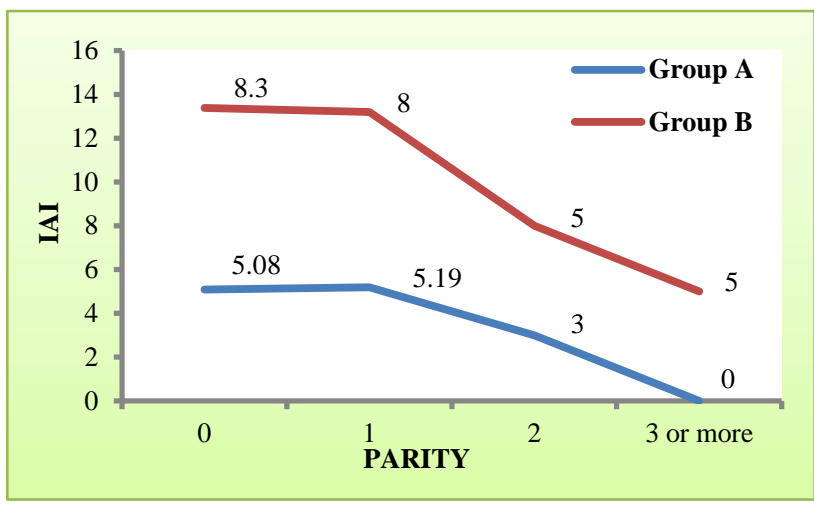

Figure 1: Effect of Parity on IAI.

The effect of parity on IAI has been depicted in the following graph which indicated that as the parity progressed, IAI shortened. Mean IAI was 2 hours shorter in multiparous than in nulliparous women in Group-A where the difference was of 3 hours in Group-B.

Table 5: Dose of misoprostol required in primigravida.

\begin{tabular}{|lllll|}
\hline $\begin{array}{l}\text { Total dose } \\
(\text { in } \mu \mathrm{g})\end{array}$ & $\begin{array}{l}\text { Group-A } \\
(\mathrm{N}=9)\end{array}$ & No. & $\%$ & $\begin{array}{l}\text { Group-B } \\
(\mathbf{N}=16)\end{array}$ \\
\hline 400 & - & & - & $\%$ \\
\hline 600 & 1 & 11.1 & - & - \\
\hline 800 & - & - & 4 & 25 \\
\hline 1000 & 7 & 77.7 & - & - \\
\hline 1200 & - & - & 2 & 12.5 \\
\hline 1400 & 1 & 11.1 & - & - \\
\hline 1600 & - & - & 7 & 43.8 \\
\hline 1800 & - & - & - & - \\
\hline 2000 & - & - & 3 & 18.8 \\
\hline 2400 & - & - & - & - \\
\hline Mean \pm S.D. & $1000 \pm 200$ & $1425 \pm 437.41$ \\
\hline P-value & 0.001 & & & \\
\hline
\end{tabular}

The mean dose of misoprostol required for complete abortion was statistically lesser in Group-A than Group-B in primigravida (Table 5) at $1000 \pm 200 \mu \mathrm{g}$ versus 1425 $\pm 437.41 \mu \mathrm{g}$ ( $\mathrm{p}=0.01)$ whereas in multigravida (Table 6), it was comparable $(\mathrm{p}=0.662) .100 \%$ of primigravida expelled with up to $1400 \mu \mathrm{g}$ of misoprostol in simultaneous group while $62.6 \%$ women in interval group required dose between 1600 to $2000 \mu \mathrm{g}$. However, the mean dose of misoprostol required to achieve complete expulsion irrespective of gravidity was significantly less in Group-A than in Group-B at a dose of $\quad 1048.00 \pm 388.50 \mu \mathrm{g}$ and $1328.00 \pm 427.00 \mu \mathrm{g}$ respectively $(\mathrm{p}=0.01)$.

Table 6: Dose of misoprostol required in multigravida.

\begin{tabular}{|lllll|}
\hline $\begin{array}{l}\text { Total dose } \\
\text { (in } \mu \mathrm{gg})\end{array}$ & $\begin{array}{l}\text { Group-A } \\
(\mathbf{N = 1 6})\end{array}$ & $\begin{array}{l}\text { Group-B } \\
(\mathbf{N = 9})\end{array}$ & No. & $\%$ \\
\hline 400 & 0 & & 0 & 0 \\
\hline 600 & 4 & 25 & 0 & 0 \\
\hline 800 & 0 & & 3 & 33.3 \\
\hline 1000 & 10 & 62.5 & 0 & 0 \\
\hline 1200 & 0 & 0 & 5 & 55.6 \\
\hline 1600 & 0 & 0 & 0 & 0 \\
\hline 2000 & 0 & 0 & 1 & 11.1 \\
\hline 2400 & 0 & 0 & 0 & 0 \\
\hline 2600 & 2 & 12.5 & 0 & 0 \\
\hline Mean \pm S.D. & $1075 \pm 466.90$ & $1155.55 \pm 370.18$ \\
\hline P value & 0.662 & & \multicolumn{2}{|l|}{} \\
\hline
\end{tabular}

The success rate was same $(76 \%)$ in both groups. 19 patients in both groups had complete expulsion of product of conception while 6 patientshad failure. These cases required additional measures i.e., intracervical insertion of Foley's catheter, oxytocin, evacuation and curettage.

Table 7: Side-effects.

\begin{tabular}{|lllll|}
\hline Side-effects & $\begin{array}{l}\text { Group-A } \\
(\mathbf{N = 2 5})\end{array}$ & \multicolumn{3}{c|}{$\begin{array}{l}\text { Group-B } \\
(\mathbf{N = 2 5})\end{array}$} \\
\cline { 2 - 5 } & No. & \% & No. & \% \\
\hline Shivering & 1 & 4 & 3 & 12 \\
\hline Nausea & 4 & 16 & 5 & 20 \\
\hline Vomiting & 5 & 20 & 6 & 24 \\
\hline Diarrhea & 3 & 12 & 7 & 28 \\
\hline Fever & 5 & 20 & 3 & 12 \\
\hline Headache & NIL & - & NIL & - \\
\hline Rupture & NIL & - & NIL & - \\
\hline
\end{tabular}

The side-effects of both regimens are shown in Table 7 having almost similar results among both the groups. However, the most common side-effects (20\%) in GroupA were vomiting and fever while diarrhea was most common side-effect in Group-B, 28\%. None were readmitted for retained products of conception. There was 
no significant difference in hemoglobin levels before and after expulsion in both groups. No blood transfusion was required.

\section{DISCUSSION}

Surgical interventions like suction and evacuation is the method of choice for first trimester abortion which ensures complete evacuation but in second trimester abortion medical methods are preferred. Advanced gestation age, firmness of cervix are the limiting factors for attaining complete expulsion in second trimester. Prostaglandins are the most widely used drugs for the same which includes PGE-1 (misoprostol), PGF-2 $\alpha$ (carboprost) and PGE-2 gel (dinoprostol). Amongst them misoprostol is the most accepted and commonly used drug for second trimester abortion.

Many studies evaluated the role of interval priming with mifepristone prior to misoprostol but few studies have determined the effectiveness of simultaneous administration of both drugs for second trimester medical abortion. $^{9,10}$ Present study is unique in terms of comparing two different regimens which are not reported earlier to the best of our knowledge.

Chai et al conducted a randomized trial to compare effectiveness of simultaneous administration of mifepristone and misoprostol versus 36-48 hours interval regimen in second trimester abortions. ${ }^{11}$ They reported a success rate of $91.5 \%$ in simultaneous regimen and $100 \%$ in interval group with significantly shorter IAI in interval (4.9 hours) compared to immediate regimen (10 hours). Mean dosage of misoprostol required was also significantly less in interval group than in immediate group $(1000 \mu \mathrm{g}$ versus $1800 \mu \mathrm{g} ; \mathrm{p}<0.001)$. However, results in present study were in contrast to above with significantly lesser IAI and misoprostol required in simultaneous group than in interval group as discussed earlier. The difference in the success rate of present study $(76 \%)$ and that by Chai et al $(91.5 \%)$ is attributed to the fact that success was defined as the expulsion of fetus, irrespective of whether evacuation was necessary because of incomplete abortion later on. However, patients who required surgical evacuation were considered as failure in present study. No other study has evaluated the role of simultaneous dose regimen in second trimester abortion. A few studies have reported success rate in first trimester complete abortion i.e., $95.1 \%$ and $92.6 \%$ respectively. ${ }^{12}$, 13

A study conducted by Nagaria et al using 12 hours interval regimen showed comparable results with present study in terms of mean dose of misoprostol required $(1186 \mu \mathrm{g})$ and but comparatively lesser IAI (6.72 hours). ${ }^{14}$ Patel et al, reported interval regimen of mifepristone and misoprostol of 24 hours apart to be better than misoprostol alone in terms of success rate, IAI and sideeffects. ${ }^{15}$ In present study, though success rate was comparable in both the groups but IAI and dose of misoprostol was significantly less in simultaneous regimen i.e., Group-A.

There was significant relationship $(\mathrm{p}=0.01)$ of gestational age and parity with IAI in present study. As the gestational age advances there was shortening of IAI from 13 weeks to 17.6 weeks and in subjects more than 17.6 weeks, IAI also prolonged. IAI was two hours shorter in multiparous women than nulliparous in GroupA and three hours in Group-B. These observations were in accordance with results of RCT conducted by Mentula et al., where they compared one day and two day dosing interval regimen of mifepristone and misoprostol in second trimester medical abortion. Median IAI was three hours longer in one day interval group when gestation was more than 16 weeks $(\mathrm{p}=0.024)$ and in nulliparous women $(\mathrm{p}=0.013) .{ }^{16}$

Furthermore, there is paucity of research in simultaneous or 12 hours interval regimen of mifepristone and misoprostol for second trimester medical abortions. A few studies have explained the effect of gestational age and parity on IAI. Present study is unique as it delineated a possibility of relation to parity and gestation with IAI. Although statistically significant differences were observed among many parameters between groups but also a large sample size and double blind RCT is required to generalize these results.

\section{CONCLUSION}

It is concluded that although success rates were same for both the regimens in achieving complete expulsion (76\%) but simultaneous administration of mifepristone and misoprostol had better results as compared to interval regimen in terms of statistically significant lower IAI and lesser total dose requirement of misoprostol. Parity, prior cervical dilatation and gestational age also had an influence on IAI where IAI is decreased with increase in parity, cervical dilatation and at advancing gestational age.

\section{Funding: No funding sources Conflict of interest: None declared}

Ethical approval: The study was approved by the Institutional Ethics Committee

\section{REFERENCES}

1. Cunningham FG, Leveno KJ, Bloom SL, Hauth JC, Rouse DJ and Spong CY. Chapter-1.Overview of Obstetrics. In: Cunningham, FG, Leveno KJ, Bloom SL, Hauth JC, Rouse DJ and Spong CY, Eds. Williams Obstetrics, 23rd Edition. New York: McGraw-Hill.2010;143.

2. Gemzell-Danielsson K, Lalitkumar S. Second trimester medical abortion with mifepristonemisoprostol and misoprostol alone: a review of methods and management. Reprod Health Matters. 2008;16(31 Suppl):162-72. 
3. Dass A, Mukhopadahyay P, Dhawan S. Termination of mid-trimester pregnancies by intra-amniotic injection of hypertonic saline. J Obstet Gynaecol India. 1975;25(3):323-30.

4. Weinberg PC, Shepard MK. Intraamniotic Urea for Induction of Mid-Trimester Abortion Obstet Gynecol. 1973;41(3):451-4.

5. Royal College of Obstetricians and Gynecologists. The care of women requesting induced abortion. Evidence-based Clinical Guideline Number 7. London: RCOG; 2011. Available at https://www.rcog.org.uk/globalassets/documents/gui delines/abortion_guideline_summary.pdf

6. Pike JE. Total synthesis of Prostaglandins. Fortschr Chem Org Naturst.1970;28:313-42.

7. Lalitkumar S, Bygdeman M, Gemzell-Danielsson K. Mid-trimester induced abortion: a review. Hum Reprod Update. 2007;13(1):37-52.

8. Sarkar NN. Mifepristone: bioavailability, pharmacokinetics and use-effectiveness. Eur J Obstet Gynecol Reprod Biol. 2002;101(2):113-20.

9. Ngoc NT, Shochet T, Raghavan S, Blum J, Nga NT, Mint NT et al. Mifepristone and misoprostol compared with misoprostol alone for second trimester abortion: a randomized controlled trial. Obstet Gynecol. 2011;118:601-8.

10. Nilas L, Glavind-Kristensen M, Vejborg T, Knudsen UB. One or two day mifepristone-misoprostol interval for second trimester abortion. Acta Obstet Gynecol Scand. 2007;86(9):1117-21.

11. Chai J, Tang OS, Hong QQ, Chen QF, Cheng LN, $\mathrm{Ng} \mathrm{E}$ et al. A randomized trial to compare two dosing intervals of misoprostol following mifepristone administration in second trimester medical abortion. Hum Reprod. 2009;24(2):320-4.
12. Creinin MD, Schreiber CA, Bednarek P, Lintu H, Wagner MS, Meyn LA. Medical Abortion at the Same Time (MAST) Study Trial Group. Mifepristone and misoprostol administered simultaneously versus 24 hours apart for abortion: a randomized controlled trial. Obstet Gynecol. 2007;109(4):885-94.

13. Li YT, Hsieh JC, Hou GQ, Chen TH, Chu YC, Lin TC et al. Simultaneous use of mifepristone and misoprostol for early pregnancy termination.Taiwan J Obstet Gynecol. 2011;50(1):11-4.

14. Nagaria T, Sirmor N. Misoprostol vs mifepristone and misoprostol in second trimester termination of pregnancy. J Obstet Gynaecol India. 2011;61(6):65962.

15. Patel U, Chauhan K, Singhi S, Kanani M. Second trimester abortion- mifepristone and misoprostol or misoprostol alone? Int J Reprod Contracept Obstet Gynecol. 2013;2:315-9.

16. Mentula M, Suhonen S, Heikinheimo O. One- and two-day dosing intervals between mifepristone and misoprostol in second trimester medical termination of pregnancy-a randomized trial. Hum Reprod. 2011;26(10):2690-7.

Cite this article as: Saini A, Bedi PK, Bhagat N. Comparative effectiveness of simultaneous administration of mifepristone and misoprostol versus interval regimen of mifepristone followed by misoprostol 12 hours apart in second trimester medical abortion. Int J Reprod Contracept Obstet Gynecol 2018;7:2449-54. 